\title{
Integration of Family Planning Services within Post Abortion Care at Health Facilities in Dessie -North East Ethiopia.
}

\author{
Awol Seid $^{1 *}$, Abebe Gebremariam², Mulumebet Abera ${ }^{2}$ \\ ${ }^{1}$ Faculty of Health Sciences, Post Box No: 395, Wollega University, Nekemte, Ethiopia \\ ${ }^{2}$ Department of Population and Family Health, Post Box No: 378, Jimma University, Jimma, Ethiopia
}

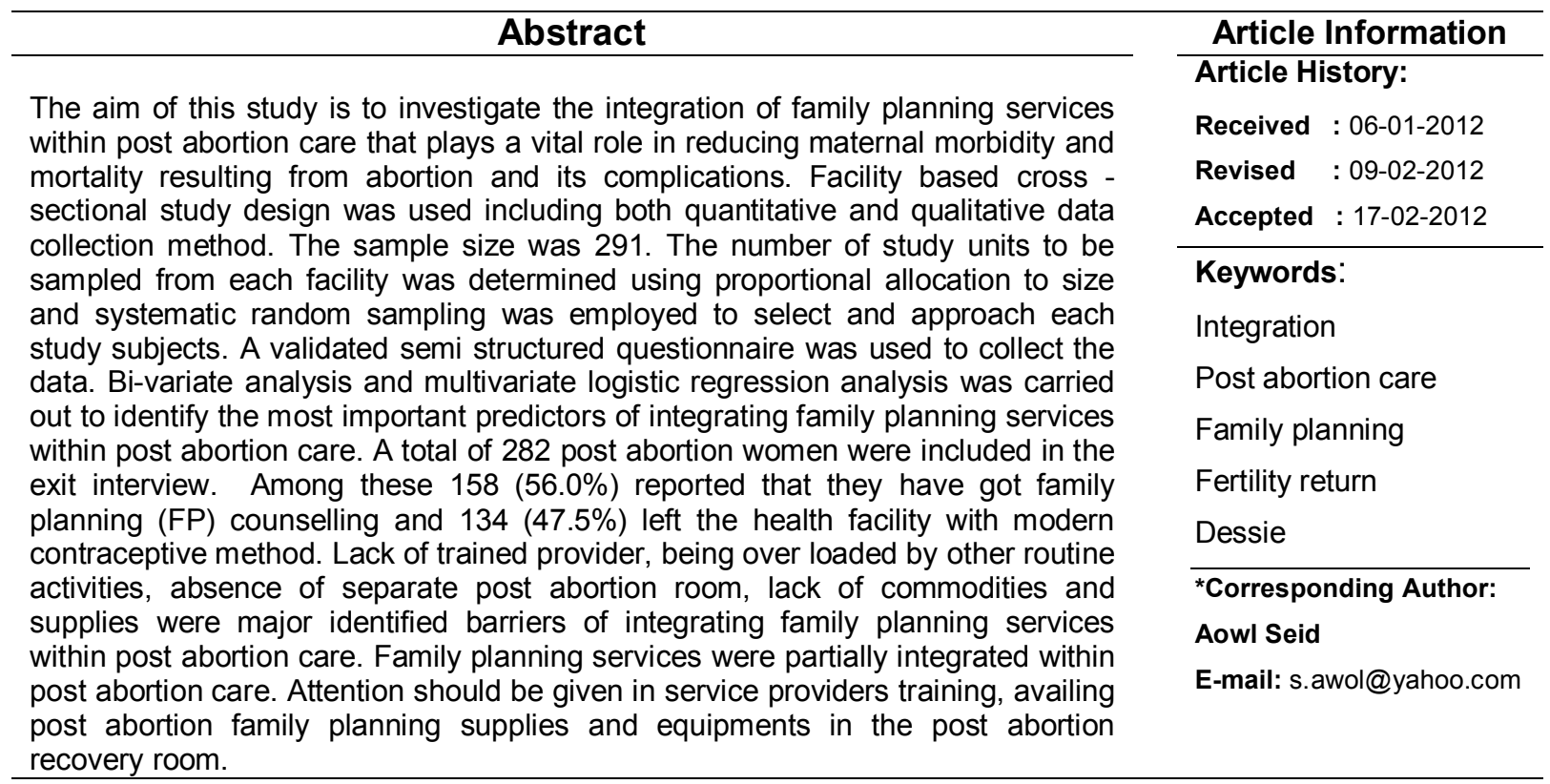

\section{INTRODUCTION}

Unsafe abortion is a major public health problem in many countries. It is one of the most easily preventable causes of maternal death and ill-health which causes about $13 \%$ of global maternal mortality and approximately $20 \%$ of overall burden long term sexual and reproductive ill-health. A woman die every eight minutes some were in developing countries due to complications arising from unsafe abortion (WHO, 2007). Providing post abortion service is a widely accepted public health strategy to reduce maternal mortality and morbidity from unsafe abortion and an opportunity to provide comprehensive reproductive health services (FHI, 2007). Providing post abortion family planning (PAFP) services and facilitating post abortal women's access help to prevent future unwanted pregnancies and break the cycle of repeat abortion (Post abortion Care Consortium Community Taskforce, 2002). Abortion care is one of the few contacts that women visit health facilities and thus becomes an opportunity for receiving family planning and other reproductive health services (Abdel-Tawab, 2009). 
A consensus statement stated by post abortion care consortium and international conference on population and development (ICPD) program of action said that if the woman we treat for abortion is there because she could not get contraception, we have failed her. If she leaves without family planning method we have failed her twice (ICPD, Post abortion Care Consortium, 1994). Based on health and health related indicators report of medical abortion without complication (safe abortion) is indicated as the fifth leading cause of health facility admission for female in Ethiopia (FMOH, 2009). Unsafe abortion accounts for nearly $60 \%$ of all gynaecologic admissions and almost $30 \%$ of all obstetric and gynaecologic admissions all together $(\mathrm{MOH}$, Family health department, 2006). Due to the clandestine nature of unsafe abortion services, however, these figures represent only the tip of the iceberg and not full magnitude of the problem.

The national reproductive health strategy and the health sector development plan (HSDP) give emphasis to improve quality and coverage of reproductive health services through integrated approach $(\mathrm{MOH}, \quad$ National reproductive health strategy, 2006). Many calls exist for integration as a way to address unmet need for family planning. Family planning services may be integrated with a wide range of other services; such as with STI/HIVIAIDS services, with post abortion care, with immunization service (Farrell, 2007). The national Ministry of Health issued guideline for implementation of safely induced abortion services in 2006 and the guideline mentioned post-abortion counselling and family planning services provision as one component of comprehensive post abortion care. $(\mathrm{MOH}$, 2006). Effectively treating abortion complications, providing family planning to prevent future unintended pregnancies and unsafe abortions, and linking women to other reproductive health services can substantially reduce the number of abortion-related death, taking a significant step toward the global goal of reducing maternal mortality (Post abortion Care Consortium task force, 2002; USAID and JHIEGO, 2002; Maureen and Katherine, 2003). Many post abortion women likely need family planning services, but unmet need for these services is often greatest. World health organization (WHO) advises that all post abortion patients receive contraceptive counselling before leaving the health facility (WHO, 2003; Elizabeth and Laura, 2006). Family planning services need to be initiated immediately during postabortion as ovulation returns as early as day 11 and usually occurs before the first menstrual bleeding. Recent WHO guidelines recommend a six month interpregnancy interval following abortion to ensure better maternal and fetal outcomes (WHO, 2006; Huntington, 2000).

There are varieties of integration strategies to bring FP services to health programs already accessed by women. The FP service integration models ranges from the simple incorporation of information about healthy timing and spacing of pregnancy, to the provision of information about referrals for available methods, to counselling and actual method provision (Dieng, 2008; Hala et al., 2007). The different models of FP service integration have their own effect on service quality, acceptability and continual use of family planning services, and cost-effectiveness ( $\mathrm{FHI}$, 2004; Monica et al., 2007). Offering services in one place at one time and by the same provider may generally be preferable for clients and ensures that their needs are met during one visit. Referring clients for related services may be more feasible and less costly for some programs, but doing so may reduce their effectiveness in ensuring that clients actually receive the services (Engender Health, 2003; Hala et al., 2007). Considering integration of family planning services within post abortion care, it is not known which integration model(s) would be more effective in different hospital settings of Ethiopia. In general, little is known about how integrated services can best be configured, and what impact they have on the service provision.

There is remarkably little empirical evidence available about integration of family planning services within post abortion care nationally \& particularly there is no study on this issue at the study area. Therefore this study aimed at providing information on the integration of family planning services within post abortion care that plays a vital role in reducing maternal morbidity and mortality resulting from unwanted pregnancy, abortion and its complications among women getting abortion care.

The specific objectives of present research are to assess the future fertility desire, knowledge on fertility return after abortion, family planning service provision among post abortion women and to investigate the integration model of providing family planning services within post abortion care at the target health facilities. The specific objectives of this research are to assess 
the future fertility desire, knowledge on fertility return after abortion, family planning service provision among post abortion women and to investigate the integration model of providing family planning services within post abortion care at the target health facilities.

\section{MATERIALS AND METHODS}

\section{Study Area and Period}

The study was conducted at health facilities providing abortion service in Dessie city, South Wollo zone, Amhara Regional state from FebApril 2010. In Dessie city administration abortion service was provided at Dessie referral hospital, Boru-Meda district hospital, Dessie health centre, three private general hospitals, two private higher clinics, Marie Stopes international and FGAE Dessie branch Reproductive health clinic.

\section{Study Design}

A facility based cross - sectional study using both quantitative and qualitative data collection method was conducted.

\section{Sample Size and Sampling Techniques}

The required sample size was determined using one-population proportion formula. A proportion 0.78 (78 \% post abortion patients received modern contraception) was taken from end line assessment study done in Tigray region (Benson et al., 2009) and it was 291. A preliminary survey at all these health facilities was done to collect the average prior two month case load, since the time for data collection was planned to be two month. The number of study units to be sampled from each facility was determined using proportional allocation to size and systematic random sampling was employed to select and approach each study subjects. Those sampled post abortion women during the data collection time at the studied facilities were the study populations.

\section{Data Collection Instrument and Methods}

The data for the quantitative study was collected using pre-tested interviewer administered semi-structured questionnaire which contain socio-demographic characteristics, previous reproductive health history, future fertility desire and post abortion family planning service related questions. The questionnaire was adopted from standard instrument designed by USAID (Rivero-Fuentes et al., 2008) and it was modified depending on the local situation and the research objectives. Client exit, service provider interview, key informant in-depth interview and observation were used to assess the same aspects of the services in order to improve validity of the conclusions or appraised different aspects of the services.

\section{Statistical Analysis}

SPSS version 16.0 statistical package soft ware was used to analyze the data. In addition to descriptive statistics, odds rations and $95 \%$ confidence interval were used to determine the strength of the associations. The logistic regression analysis model was used to assess the relative effect of variables.

\section{Ethical Consideration}

The proposal was approved by Ethical Review Committee of college of Public Health and medical science of Jimma University before the conduct of the study. Letter of permission was obtained from the Dessie city administration and Zonal department health office. All the study participants were informed about the purpose of the study and finally their written consent was obtained prior to interviewing them.

\section{RESULTS AND DISCUSSION}

A total of 282 post abortion women were included making a response rate of $97.0 \%$. One hundred seventy eight $(63.1 \%)$ of them were in the youth age group (15-24 year). One hundred fifty-seven $(55.7 \%)$ of study subjects were urban dwellers. One hundred sixty four $(58.2 \%)$ attained secondary and above school. Majority 258 (91.5\%) were Amhara by ethnicity. One hundred thirty five $(48 \%)$ of respondents were married. By religion little more than half $(56.7 \%)$ were Islam. By occupation $82(29.1 \%)$ were student, $75(26.6 \%)$ were house wife (Table 1).

Among the total studied women, 132 (46.8\%) had history of previous pregnancy, out of which, $35(26.5 \%)$ reported one or more previous history of abortion. Majority (92.2\%) said that the index pregnancy which resulted in abortion was unwanted. Ninety two (32.6\%) of the study subjects used modern contraceptive during the event of the index pregnancy. The gestational age of the index pregnancy ranged from 2 to 27 weeks and $240(85 \%)$ of them were aborted at 12 weeks of gestational age and below. 
Table 1: Socio-demographic characteristics of post abortion women at the study health facilities in Dessie, North-East Ethiopia, Feb-April, 2010.

\begin{tabular}{|c|c|}
\hline Characteristics & $\mathbf{N}(\%)$ \\
\hline $\begin{array}{l}\text { Age(year) } \\
15-24 \\
25-34 \\
35-45\end{array}$ & $\begin{array}{l}178(63.1) \\
91(32.3) \\
13(4.6)\end{array}$ \\
\hline $\begin{array}{l}\text { Educational level } \\
\text { Can't read and write } \\
\text { Only read and write } \\
\text { Primary school first cycle (1-4) } \\
\text { Primary school second cycle(5-8) } \\
\text { Secondary school and above }\end{array}$ & $\begin{array}{l}44(15.6) \\
9(3.2) \\
23(8.4) \\
42(14.9) \\
144(58.2)\end{array}$ \\
\hline $\begin{array}{l}\text { Residence } \\
\text { Urban } \\
\text { Semi-urban } \\
\text { Rural }\end{array}$ & $\begin{array}{l}157(55.7) \\
67(23.8) \\
58(20.8)\end{array}$ \\
\hline $\begin{array}{l}\text { Religion } \\
\text { Muslim } \\
\text { Orthodox Christian } \\
\text { Protestant }\end{array}$ & $\begin{array}{l}160(56.7) \\
114(40.4) \\
8(2.8)\end{array}$ \\
\hline $\begin{array}{l}\text { Ethnicity } \\
\text { Amhara } \\
\text { Oromo } \\
\text { Afar } \\
\text { Tigrae }\end{array}$ & $\begin{array}{l}258(91.5) \\
8(2.8) \\
7(2.5) \\
9(3.2)\end{array}$ \\
\hline $\begin{array}{l}\text { Marital status } \\
\text { Married } \\
\text { Unmarried ( Single and have fiancé/friend) } \\
\text { Past married (Divorced \& widowed) }\end{array}$ & $\begin{array}{l}135(48) \\
118(41.8) \\
29(10.3)\end{array}$ \\
\hline $\begin{array}{l}\text { Family size } \\
1-4 \\
\geq 5\end{array}$ & $\begin{array}{l}196(69.5) \\
86(30.5)\end{array}$ \\
\hline Total & $282(100)$ \\
\hline
\end{tabular}

Two hundred twenty $220(78 \%)$ of the studied women desired to be pregnant again, out of which, $213(96.8 \%)$ decided to wait for more three month before becoming pregnant again. This finding is higher than as compared to the study finding done in 2002 in Addis Ababa (Yilma et al., 2003) and the finding of a study conducted in Amhara and Oromia region (Solomon, 2008) that about $82 \%$ and $43.7 \%$ of respondents reported not having a plan to become pregnant in three months period following the abortion respectively. This implies the importance of family planning service for women seeking or undergoing abortion care.

The result of this study indicated that $96(34 \%)$ of the studied women reported they were informed about the time period that a woman could be ovulate and become pregnant again following abortion. Out of which $92.4 \%$ were told as they could ovulate after fifteen days following abortion. This is inconsistent with literatures that stated ovulation might return as early as day 11 and usually before the first menstrual bleeding following abortion (Huntington, 2000). This result is supported by the observation finding that in $13.6 \%$ observed cases the providers explained an immediate risk of repeat pregnancy if she did not use a contraceptive method. In majority of the cases the important opportunity to aware the immediate return of ovulation was missed 
Table 2. Multivariate logistic analysis of factors influencing provision of post abortion modern contraception at study facilities in Dessie, North-East Ethiopia, Feb-April, 2010.

\begin{tabular}{|c|c|c|c|c|}
\hline \multirow[b]{2}{*}{ Variable } & \multicolumn{4}{|c|}{ Post Abortion Modern Contraceptive Method Provided } \\
\hline & Yes & No & $\operatorname{COR}(95 \%$ C.I) & AOR(95\% C.I) \\
\hline $\begin{array}{c}\text { Ownership of the Health Facility } \\
\text { Public } \\
\text { Private } \\
\text { NGO }\end{array}$ & $\begin{array}{c}9 \\
10 \\
115\end{array}$ & $\begin{array}{l}42 \\
64 \\
42\end{array}$ & $\begin{array}{l}0.08(0.03,0.17)^{*} \\
0.06(0.03,0.12)^{*} \\
1\end{array}$ & $\begin{array}{l}0.27(0.06,1.26) \\
0.01(0.001,0.08)^{*} \\
1\end{array}$ \\
\hline $\begin{array}{l}\text { Level of Health Facility } \\
\text { Referral Hospital } \\
\text { General Hospital } \\
\text { Health Center \& Clinic }\end{array}$ & $\begin{array}{c}2 \\
13 \\
119\end{array}$ & $\begin{array}{l}37 \\
41 \\
70\end{array}$ & $\begin{array}{l}0.03(0.01,0.14)^{*} \\
0.19(0.09,0.37)^{*} \\
1\end{array}$ & $\begin{array}{l}0.07(0.007,0.73) \text { * } \\
7.34(1.17,45.99) \text { * } \\
1\end{array}$ \\
\hline $\begin{array}{l}\text { Duration at the Health Facility } \\
\qquad \begin{array}{c}\leq \mathrm{hr} \\
>2 \mathrm{hr}\end{array}\end{array}$ & $\begin{array}{l}47 \\
87\end{array}$ & $\begin{array}{c}21 \\
127\end{array}$ & $\begin{array}{c}3.3(1.83,5.85)^{*} \\
1\end{array}$ & $\begin{array}{c}1.63(0.78,3.35) \\
1\end{array}$ \\
\hline $\begin{array}{c}\text { Age(year) } \\
15-24 \\
\geq 25\end{array}$ & $\begin{array}{l}93 \\
41\end{array}$ & $\begin{array}{l}85 \\
63\end{array}$ & $\begin{array}{c}1.7(1.03,2.75)^{*} \\
1\end{array}$ & $\begin{array}{c}0.73(0.30,1.78) \\
1\end{array}$ \\
\hline $\begin{array}{l}\text { Residence } \\
\text { Urban } \\
\text { Semi-urban } \\
\text { Rural }\end{array}$ & $\begin{array}{l}93 \\
19 \\
22\end{array}$ & $\begin{array}{l}64 \\
48 \\
36\end{array}$ & $\begin{array}{c}2.4(1.3,4.4)^{*} \\
0.65(0.3,1.4) \\
1\end{array}$ & $\begin{array}{c}1.4(0.58,3,57) \\
1.0(0.36,2.96) \\
1\end{array}$ \\
\hline $\begin{array}{l}\text { Marital Status } \\
\text { Married } \\
\text { Past married } \\
\text { Unmarried }\end{array}$ & $\begin{array}{c}62 \\
9 \\
63\end{array}$ & $\begin{array}{l}73 \\
20 \\
55\end{array}$ & $\begin{array}{l}0.74(0.45,1.22) \\
0.39(0.16,0.93)^{*} \\
1\end{array}$ & $\begin{array}{c}1.14(0.46,2.84) \\
0.44(0.12,1.62) \\
1\end{array}$ \\
\hline $\begin{array}{c}\text { Occupation } \\
\text { Housewife } \\
\text { Student } \\
\text { Government employee } \\
\text { Others }\end{array}$ & $\begin{array}{l}31 \\
49 \\
16 \\
38\end{array}$ & $\begin{array}{l}44 \\
33 \\
25 \\
46\end{array}$ & $\begin{array}{c}1 \\
2.1(1.11,3.98)^{*} \\
0.9(0.42,1.98) \\
0.17(0.62,2.20)\end{array}$ & $\begin{array}{c}1 \\
1.3(0.34,3.58) \\
0.61(0.19,1.90) \\
1.04(0.39,2.82)\end{array}$ \\
\hline $\begin{array}{c}\text { Previous history of pregnancy } \\
\text { Yes } \\
\text { No }\end{array}$ & $\begin{array}{l}50 \\
84\end{array}$ & $\begin{array}{l}82 \\
66\end{array}$ & $\begin{array}{c}1 \\
2.1(1.30,3.36)^{*}\end{array}$ & $\begin{array}{c}1 \\
1.3(0.51,3.24)\end{array}$ \\
\hline $\begin{array}{c}\text { Want the index pregnancy } \\
\text { Yes(wanted) } \\
\text { No (unwanted) }\end{array}$ & $\begin{array}{c}3 \\
131\end{array}$ & $\begin{array}{c}19 \\
129\end{array}$ & ${ }^{1} 6.4(1.86,22.26)^{*}$ & $\begin{array}{c}1 \\
2.2(0.213-23.23)\end{array}$ \\
\hline $\begin{array}{l}\text { Gestational age of index pregnancy } \\
\qquad \begin{array}{c}\leq 12 \text { week } \\
>12 \text { week }\end{array}\end{array}$ & $\begin{array}{c}129 \\
5\end{array}$ & $\begin{array}{l}111 \\
37\end{array}$ & $\begin{array}{c}8.6(3.2,22.64)^{*} \\
1\end{array}$ & $\begin{array}{c}0.35(0.07-1.70) \\
1\end{array}$ \\
\hline $\begin{array}{c}\text { Used modern FP during the index Preg. } \\
\text { Yes } \\
\text { No }\end{array}$ & $\begin{array}{l}56 \\
78\end{array}$ & $\begin{array}{c}36 \\
112\end{array}$ & $\begin{array}{c}2.23(1.34,3.72)^{*} \\
1\end{array}$ & $\begin{array}{c}2.3(1.12-4.67) \text { * } \\
1\end{array}$ \\
\hline $\begin{array}{l}\text { Types of abortion } \\
\text { Spontaneous } \\
\text { Induced }\end{array}$ & $\begin{array}{c}6 \\
128\end{array}$ & $\begin{array}{c}32 \\
116\end{array}$ & $5.9(2.4,14.58)^{\star}$ & $0.91(0.15-5.60)$ \\
\hline $\begin{array}{c}\text { Abortion procedure } \\
\text { Medical abortion } \\
\text { Manual vacuum aspiration } \\
\text { Other method (D\&C and E\&C) }\end{array}$ & $\begin{array}{c}82 \\
46 \\
6\end{array}$ & $\begin{array}{l}33 \\
55 \\
60\end{array}$ & $\begin{array}{c}24.8(9.79,63.07)^{*} \\
8.36(3.31,21.11)^{*} \\
1\end{array}$ & $\begin{array}{c}1.7(0.35,8.56) \\
2.23(0.52,9.52) \\
1\end{array}$ \\
\hline
\end{tabular}




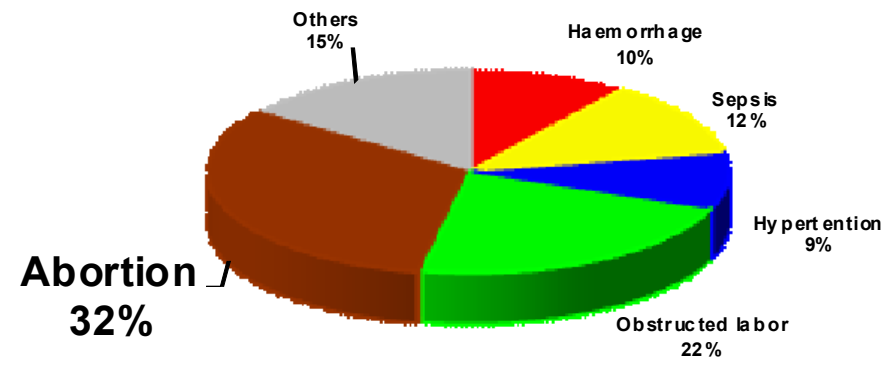

Figure 1. Share or avoruon ior maternal ueann in Ethiopia, 2003.

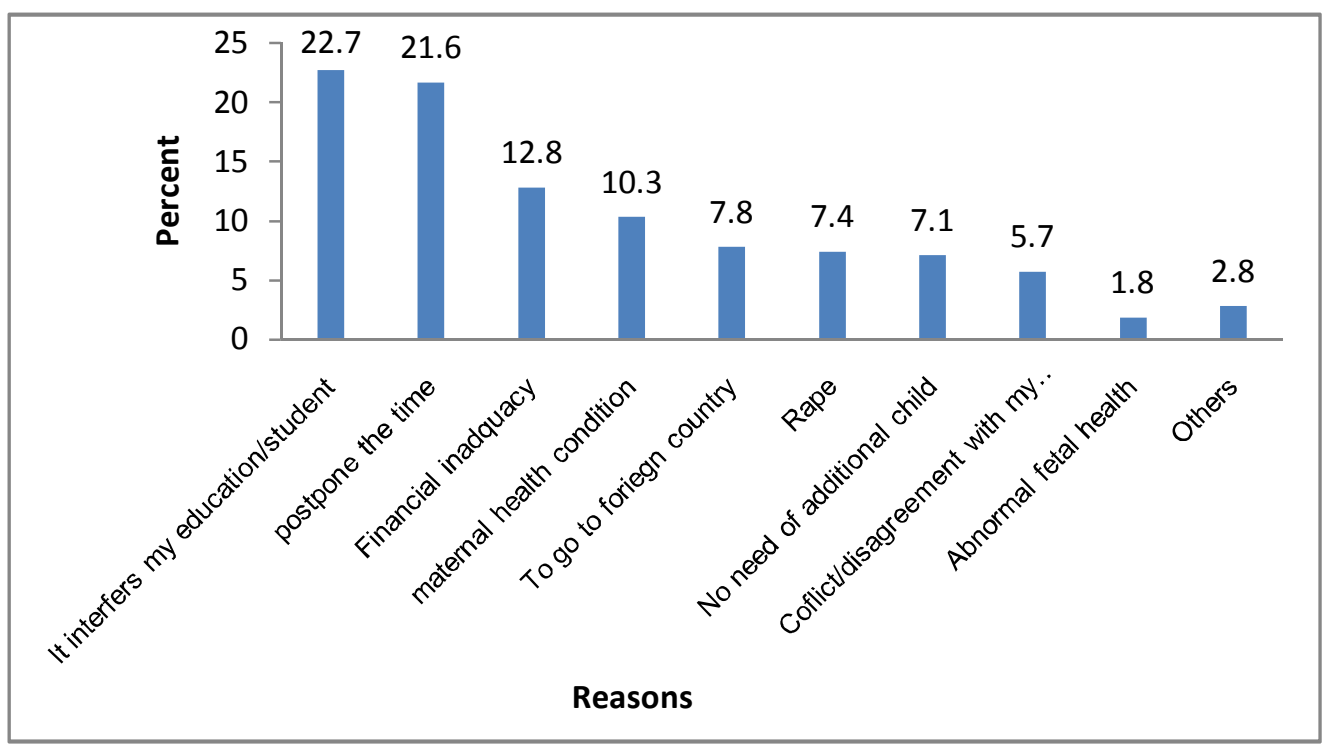

Figure 2. Reported reasons for terminating the index pregnancy at the study facilities in Dessie, North-East Ethiopia, Feb- April, 2010.

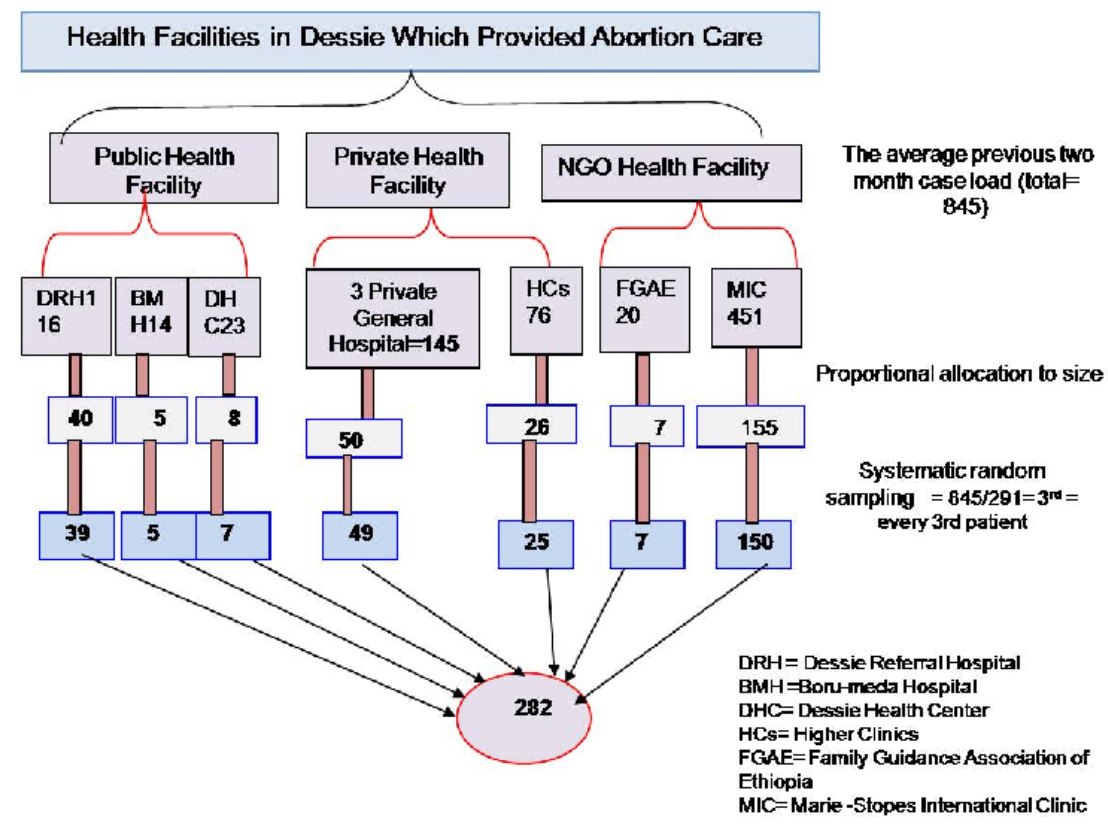

Figure 3. Schematic presentation of sampling procedure for the selection of study units in Dessie town, South Wollo Zone, Amhara Region during 2010. 
One hundred fifty eight $(56 \%)$ of the respondents reported that they have got contraceptive counselling/ information from the service provider and $134(47.5 \%)$ left the health facility with contraceptive methods. Out of which 90(67.3\%) has taken injectables DepoProvera $\AA, 24(18 \%)$ oral contraceptive pills, $15(11 \%)$ implant and $5(3.7 \%)$ condom. No one had been referred to other health facility for family planning service. It shows improvement as compared to the survey result obtained from a study done at health facilities in Addis Ababa, Amhara and Oromia which revealed that $80 \%$ of interviewed women didn't get post abortion family planning methods (Hailu et al., 2003). But these findings of this survey are less as compared to the end line assessment finding of Tigray region (Benson et al., 2009) that $78 \%$ of post abortion women received modern contraception before they left the health facility, this difference might be due to the implemented pilot project after the baseline assessment in Tigray region like service provider training, setting up post abortion room and availing of wide range of contraceptive methods. The finding of this research concerning integrating family planning services within post abortion care was not encouraging as compared to evidences from foreign studies conducted in Bolivia, Burkina Faso, Kenya, Mexico, Peru (Huntington, 2000) and the Tanzania research in 2007 (Kragelund-Nielsen et al., 2009). One explanation for this difference is that findings from these countries were post interventions that were taken to improve post abortion care services.

From this one can detect that majority of the respondents have intention to delay next pregnancy, this indicates critical demand for post abortion family planning services, however, the opportunity to provide this services was not fully utilized; this implies call for increased effort should be spent on making family planning services available and acceptable for post abortion women.

Most of the studied facilities used onsite provision of family planning services at post abortion/delivery room /gynaecology ward or at the same room where the abortion procedure is performed. This finding keeps in touch with the Egypt model based analysis research finding that onsite provision both FP counselling and offering FP methods at the post abortion recovery room/ Gynaecology ward was proved to be effective than provision of FP counselling and referral of those patients to any family planning clinic near their residence (Yossef et al., 2007). This study result showed that even though the place various, family planning services were provided by the staff from the abortion care unit, this was proved to be effective in Kenya (Solo, 1999) and Egypt (Abdel-Tawab, 2009) as compared to provision of FP services at post abortion room /Gynaecology ward by MCH-FP staff from the clinic and at the facility FP clinic through referral. Majority of service providers chose onsite provision model of integrating family planning services within post abortion care by the abortion unit staff. They pointed out the reasons behind choosing this model such as maintaining the privacy and confidentiality issues of the patients, saves the time of the patients, increase satisfaction of both service providers and to ensure prompt use of contraception.

After controlling for possible confounding in multivariate logistic analysis ownership of the health facility, level of the health facility and previous use of modern contraceptive during the index pregnancy were persisted to be significantly associated with provision of post abortion FP methods $(p<0.05)$ (Table 2). Majority of the service provides mentioned lack of training in comprehensive safe/post abortion care, being over loaded by other routine activities, absence of separate post abortion room and lack of commodities and supplies as major difficulties that hinder provision of post abortion family planning services effectively and properly.

\section{CONCLUSION}

Significant proportion of post abortion women left the health facility without getting family planning counselling and contraceptive method. Most of the studied facilities used onsite provision of FP services at post abortion/delivery room or at the same room where the abortion procedure is performed.

Lack of training in comprehensive safe/post abortion care, absence of separate post abortion care room, lack of commodities and supplies and being over loaded by other routine activities were the major identified barriers of integrating post abortion FP services within post abortion care. Thus to maximize utilization of this important opportunity for offering family planning services. 
- Health facilities have to organize separate space/room for provision of post abortion family planning services.

- Due attention should be given in availing, scaling up and sustaining wider range of post abortion family planning commodities in the post abortion unit/gynecology ward.

- Service providers should provide brief information about fertility return following abortion and detail counselling family planning for post abortion women by giving adequate time.

- Service providers have to get training on comprehensive post abortion care and on integration of family planning services with other maternal and child health services.

\section{Acknowledgment}

I would like to express my heartfelt gratitude to my advisor Prof. Abebe G., Mariam and Mulumebet Abera for their unreserved encouragements and provision of constructive comments and Jimma University for funding my thesis. I am also grateful to the Dessie city administration health office, Zone Health department and data collectors and respondents without whom this thesis would not have been realized.

\section{REFERENCE}

Abdel-Tawab, N. (2009). Challenges \& opportunities in providing post abortion family planning services. Ifrane Area, Egypt.

Benson, J., Alemayehu, T., Otsea K., Joan, H. (2009). Monitoring Safe Abortion Services in Ethiopia: Testing a model to improve service availability, use and quality.

Dieng, T. (2008). Assessment of progress of the Post abortion Care Initiative in francophone Africa. Frontiers Final Report. Washington, DC: Population Council.

Elizabeth, W. and Laura Raney. (2006). Emergency Contraception: A Necessary Component of Post abortion Family Planning Services. PAC in Action.

Engender health. (2003). Final Assessment of LongTerm and Permanent Contraception (LTPC) and Post abortion Care (PAC) Programs 1999-2003. Malawi.

Family health international (FHI). (2004). Family Planning and HIV Service Integration. 23(3).

Family Health International (FHI). (2007). Operations research study to improve post abortion care services among adolescents in the Dominican Republic. NO.WP07-02:20-5.
Federal Democratic Republic of Ethiopia. Ministry of health. (2006). National reproductive health strategy. 2006-2015.

Federal Minister of Health, (2009). 2001 EFY Health and Health Related Indicators.

Farrell., Betty, L. (2007). Family planning-integrated HIV services: A framework for integrating family planning and antiretroviral therapy services. New York: The ACQUIRE Project/Engender Health.

Gebreselassie, H. and Tamara, F. (2002). Responding to unsafe abortion in Ethiopia: A facility-based assessment of post abortion care services in public health sector facilities in Ethiopia; Chapel Hill, NC, Ipas.

Hailu, Y., Tenaw, A., Hailemichael, G., Mulu, M. (2003). The potential role of private health sectors in expanding post abortion care in Addis Ababa, Amhara, and Oromia regions of Ethiopia. Ethiopian Journal of Health Development 17 (3): 157 -165.

Hala, Y., Nahla, A., John, B. (2007). Linking family planning with post abortion services in Egypt: Testing the feasibility, acceptability and effectiveness of two models of integration. Frontiers final report. washington, DC: Population Council.

Huntington, D. (2000). Meeting Women's Health Care Needs after Abortion. Program Briefs.1.Washington, D.C.: Population Council.

International Conference on Population and Development (ICPD). (1994). Post abortion Care Consortium, Egypt, Cairo.

Maureen, R. Corbett. and Katherine L. Turner. (2003). Essential Elements of Post abortion Care: Origins, Evolution and Future Directions. International Family Planning Perspectives 29(3): 75-89.

Monica, W., Ian, A., Nzoya, M., Saumya, R., Rick H. (2007). Assessing the feasibility, acceptability and cost of introducing post abortion care in health centres and dispensaries in rural Tanzania. Frontiers Final Report. Washington, DC: Population Council.

Ministry of health, Family health department. (2006). Technical and Procedural Guidelines for Safe Abortion Services in Ethiopia.

Post abortion Care Consortium Community Task Force. (2002). Essential Elements of Post abortion Care: An Expanded and Updated Model.

Rivero, F., Saumya, R., Ricardo, E., Charlotte, W., Saiqa, M., Harriet, B., Ian A., John, T., Susana, M. (2008). Assessing integration methodology (AIM): A handbook for measuring and assessing the integration of family planning and other reproductive health services. Frontiers Manual. Washington, DC: Population Council. 
Solomon, K., Yilma, M., Hailu, Y. (2008). Quality of post-abortion care in public health facilities in Ethiopia. Ethiopian Journal of Health Development 22 (1): 26-33.

Solo, J., Billings, D., Aloo-Obunga, C., Ominde, A., Maumi, M. (1999). Creating linkages between incomplete abortion treatment and family planning services in Kenya. Studies in family planning 30(1): 17-27.

World Health Organization. (2003). Safe abortion: Technical and Policy Guidance for Health Systems. Geneva. .

World Health Organization. (2006). Report of a WHO Technical Consultation on Birth Spacing. Geneva.
World Health organization. (2007). Unsafe abortion: Global and regional estimates of incidence of unsafe abortion and associated mortality in 2003. 5th edition, Geneva.

USAID and JHIEGO. (2002). Post abortion care individual learning package: supervisors Guide.

Yilma, M., Fikre, E., Ahmed, A., Hailemichael, G., Lukman, Y. (2003). Fertility awareness and postabortion pregnancy intention in Addis Ababa, Ethiopia. Ethiopian Journal of Health Development 17(3):167-174. 